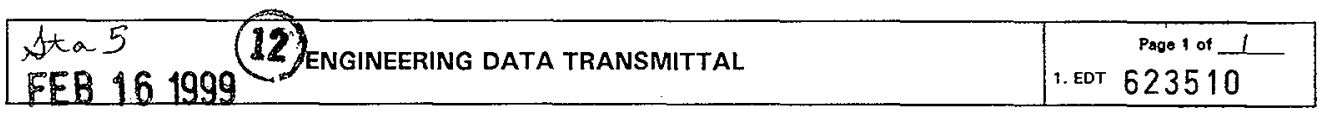

\begin{tabular}{|l|l|}
\hline $\begin{array}{l}\text { 2. To: (Receiving Organization) } \\
\text { Engineering Files }\end{array}$ & $\begin{array}{l}\text { 3. Froma (originating Organization) } \\
\text { WRAP Engineering }\end{array}$ \\
\hline 5. Proj./Prog./Dept./Div.: & $\begin{array}{l}\text { 6. Design Authority/ Design Agent/Cog. } \\
\text { Engr.: } \\
\text { WRAP Facility/WMH }\end{array}$ \\
\hline 8. Originator Remarks: & \\
This EDT is to release supporting documentation for the WRAP \\
Facility to Engineering Files for retention and retrieva1
\end{tabular}

11. Receiver Remarks: 11A. Design Baseline Document? [X] Yes [] Ho

4. Related EDT HO.:

$N / A$

7. Purchase Order No.:

N/A

9. Equip./Component No.:

$\mathrm{N} / \mathrm{A}$

10. System/Bldg./Facillty:

2336-W

12. Major Assm. Dwg. No.:

N/A

13. Permit/Permit Application No.: N/A

14. Required Response Date: N/A

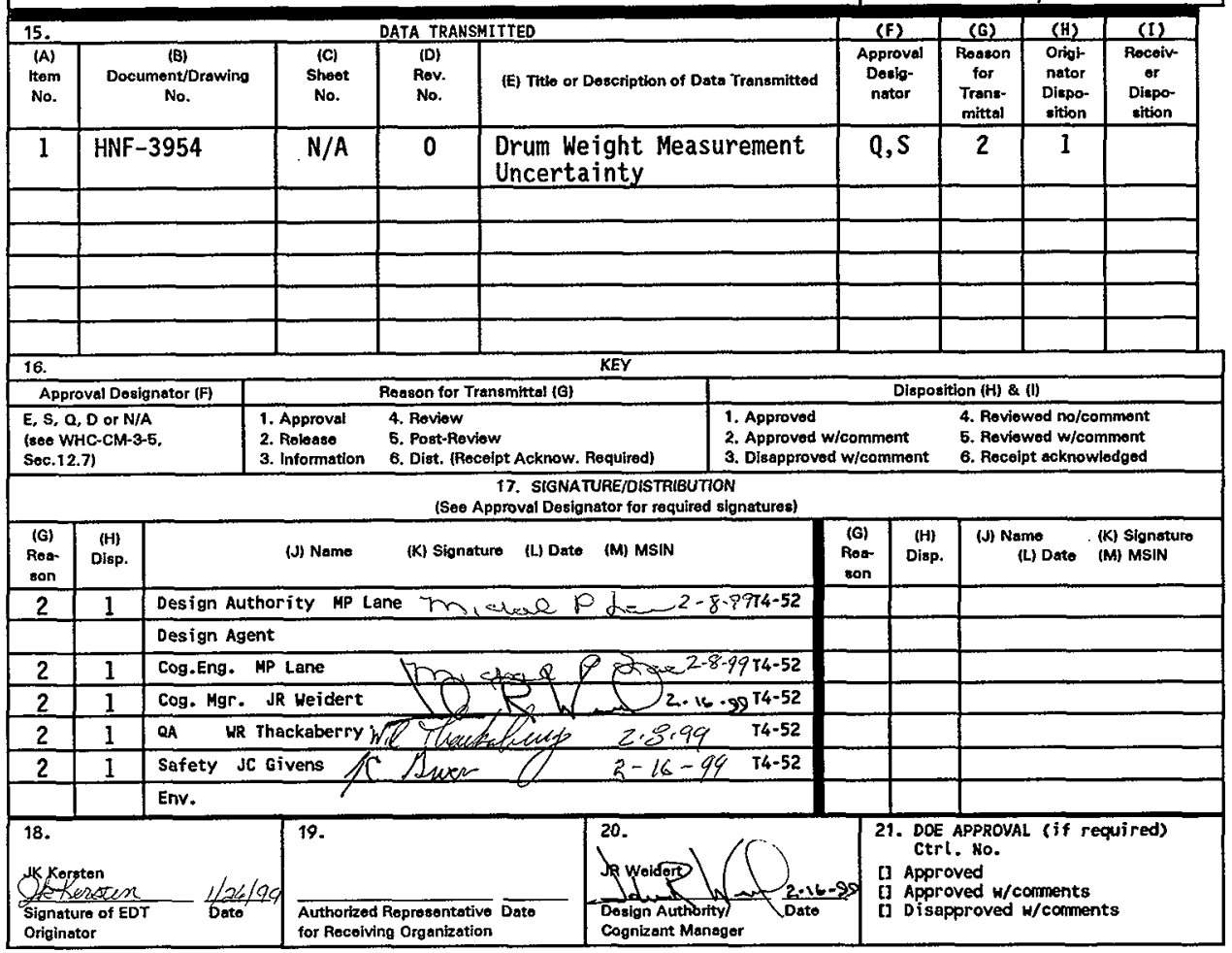

BD-7400-172-2 (05/96) GEF097 


\section{WASTE RECEIVING AND PROCESSING DRUM WEIGHT MEASUREMENT UNCERTAINTY REVIEW FINDINGS}

MP Lane

Waste Management Federal Services of Hanford, Inc., Richland, WA 99352 U.S. Department of Energy Contract DE-AC06-96RL13200

$\begin{array}{lll}\text { EDT/ECN: } & \text { EDT-623510 } & \text { UC: } 506 \\ \text { Org Code: } & 32600 & \text { Charge Code: }{ }_{\text {AJ60 }} \\ \text { B\&R Code: } & \text { EW02J126 } & \text { Total Pages: } 23\end{array}$

Key Words: WRAP, Weight Scales, NDE, NDA

Abstract: The purpose of reviewing the weight scale operation at the WRAP facility was to determine the uncertainty associated with weight measurements. Weight measurement uncertainty is needed to support WRAP Nondestructive Examination (NDE) and Non-destructive Assay (NDA) analysis.

** Fairbanks H90-5200 is a registered trademark of Fairbanks Scales, Inc., Kansas City, Mo.

** Rice Lake Scales is a registered trademark of Rice Lake Weighing Systems, Rice Lake, WI.

IRADEMARK DISCLAIMER. Reference herein to any specific commercial product, process, or service by trade name, trademark, manufacturer, or otherwise, does not necessarily constitute or imply its endorsement, recommendation, or favoring by the United states Government or any agency thereof or its contractors or subcontractors.

Printed in the United States of America. To obtain copies of this document, contact: Document Control Services, P.O. Box 950, Maitstop H6-08, Richland WA 99352, Phone (509) 372-2420; Fax (509) 376-4989.

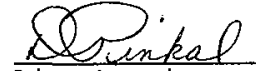

Release Approval
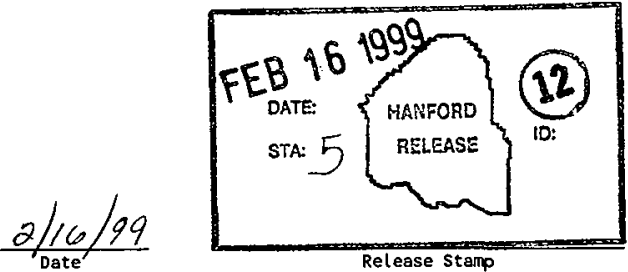
Waste Receiving and Processing Facility

\section{Drum Weight Measurement Uncertainty Review Findings}

John R. Weidert

Michael P. Lane 


\section{Table of Contents}

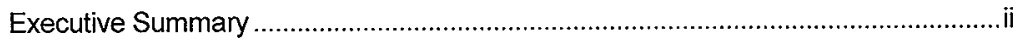

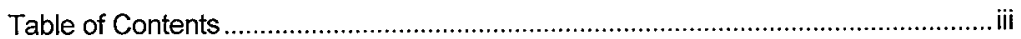

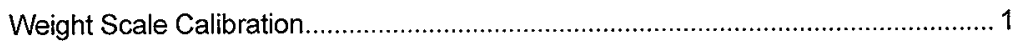

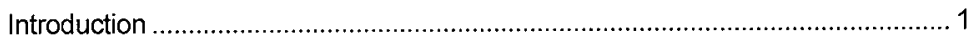

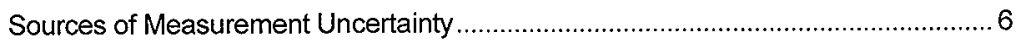

Statistically Evaluated Measurement Uncertainties ................................................ 6

Measurement Uncertainties Not Statistically Evaluated ...................................... 9

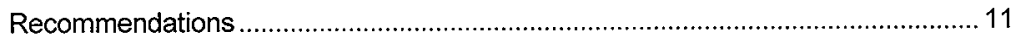

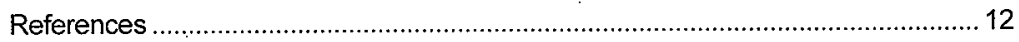




\begin{tabular}{|c|c|c|}
\hline \multicolumn{3}{|c|}{$\begin{array}{c}\text { Table } 1 \text {-- Calibration Weight Tolerances } \\
\text { (Weight Set } 403-86-02-001)\end{array}$} \\
\hline Weight & Weight ID Number & $\begin{array}{l}\text { Measurement } \\
\text { Uncertainty }\end{array}$ \\
\hline 1000 pounds & $810 \mathrm{~F}$ & $0.0064 \mathrm{~kg}$ \\
\hline 500 pounds & $813 \mathrm{~F}$ & $0.0022 \mathrm{~kg}$ \\
\hline 250 pounds & $815 \mathrm{~F}$ & $0.0001 \mathrm{~kg}$ \\
\hline
\end{tabular}

The uncertainty associated with standard weights must be less than or equal to onefourth the required weight uncertainty for weight scale calibration ${ }^{5}$. For example, to calibrate a scale to within \pm 0.1 kilograms, the uncertainty associated with each standard weight must be equal to or less than \pm 0.025 kilograms. Based on this requirement, and the largest weight uncertainty noted $( \pm 0.0064 \mathrm{~kg})$, this set of standard weights could be used to calibrate a weight scale to within $\pm\left(4{ }^{*} 0.0064\right.$ $\mathrm{kg})$, or \pm 0.03 kilograms.

In contrast, the scale calibration procedure specifies a 1000 kilogram (2204 pound) span with all required readings within $0.1 \%$ of full span ( \pm 1 kilogram). For example, by procedure, a measurement between 247.8 and 252.2 pounds would be acceptable for a 250-pound standard weight *

The \pm 1 -kilogram tolerance may allow too much uncertainty to support NDE and NDA analyses. To estimate the uncertainty associated with the existing calibration procedure, a spreadisheet was developed (Appendix A of this document). The two factors used to drive this simulation were 1) The number of measurements taken and 2) The expected uncertainty associated with each measurement.

Both factors significantly affect calibration results and can be used to reduce measurement uncertainty, if required, to support NDE or NDA analyses. For example, based on the simulation, doubling the number of weight measurements from three to six can cut the weight measurement uncertainty in half. Reducing the weight measurement tolerance from \pm 1 -kilogram to \pm 0.3 -kilogram can reduce the final weight uncertainty by a factor of three.

Weight scale calibrations should incorporate Statistical Process Control (SPC) techniques to provide a weight measurement uncertainty value. If the amount of weight measurement uncertainty must be reduced to support NDE and/or NDA analyses, weight scale calibration procedures should be modified to decrease the acceptable weight tolerance and increase the number of replicate measurements taken. The weight scale calibration should be verified on a periodic basis. The

"A certified reference material (CRM), prepared using National Institute of Standards and Technology (NIST) traceable methods 
shown as a line through the center of the chart. It is bounded above and below by "Control Limits". The limits are initially calculated based on the standard deviation of the replicate measurements. Control limits are typically set at either two or three standard deviations from the mean value.

A check weight is then measured on a periodic basis, typically as part of normal operation of the weight scale. The measured values for the check weight are recorded and plotted on the chart, usually by hand, to provide an "operational check" of weight scale operation. Those values that fall outside the control limits are considered "out of control" and must be investigated ".

One consequence of using statistical process control techniques, such as X-bar charts, is that control limits are established independently for each weight scale. This can be a problem if each scale must be treated as functionally identical to all other WRAP weight scales. One possible method for dealing with different weight scales is to set a "worst case", conservative upper limit for weight scale measurement uncertainty. Each weight scale would be calibrated to operate within this "worst case" uncertainty limit. While the performance of each scale would be individually tracked, the "worst case" value would be used to support analysis calculations.

The existing calibration procedure does not explicitly address several weight scale parameters. These parameters can materially affect the results provided by the weight scale. Table 2 lists these parameters and recommended settings. In addition, according to manufacturer instructions, the gain, offset, and analog filter settings should be optimized before weight scale use. The weight scale service manual provides instructions for performing these adjustments ${ }^{6}$. All relevant settings should be verified and explicitly recorded on the calibration data sheet before each scale is put into service.

The calibration procedure provides weights in units of pounds. To reduce the possibility for human error and to allow direct data entry into the scale during calibration, all weights should be specified in kilograms. Future standard weights should be specified in kilograms. Similarly, the weight scale capacity should be provided in kilograms.

Because the drums accepted for processing at WRAP are limited to 1000 pounds, a scale capacity of 1250 pounds, rather than 1000 kilograms is appropriate. By reducing this value, the currentiy available standard weights more closely match the scale capacity.

For commercial operation, electronic weight scales typically have a password protection scheme to prevent unauthorized access and modification of weight scale parameters. The scales observed have been configured by maintenance personnel to provide the highest security level available by disabling front panel programming to

- A complete discussion of statistical process control techniques is beyond the scope of this review. Additional details are available via consultation. 


\section{Sources of Measurement Uncertainty}

Measurement uncertainty is defined as the "parameter associated with the result of a measurement that characterizes the dispersion of the values that could reasonably be attributed to the measureand" 7 .

Measurement uncertainty generally results from sources that may be classified as ${ }^{8}$ :
A. Items which can be statistically evaluated.
B. Items which can not be statistically evaluated.

The values for both type $A$ and type $B$ uncertainties are combined to produce a final uncertainty value. The values can be combined by simple addition, but this conservative approach tends to overstate the total measurement uncertainty. For most applications, including weight measurements at WRAP, combining independent error values using a "root sum of squares" method, as outlined in NIST Technical Note $1297^{\circ}$, should be sufficient.

\section{Statistically Evaluated Measurement Uncertainties}

Several sources of measurement uncertainty can be statistically evaluated. For example, the amount of random fluctuation in weight scale readings can be estimated using statistical methods. Typically, the standard deviation of the mean of a series of replicate measurements is used to evaluate "type $A$ " measurement uncertainty. For example, a weight, or series of weights can be repeatedly measured. This data would be used to calculate a standard deviation of the measurement error. This standard deviation would then be used to calculate a confidence interval for weight scale measurements.

By convention, uncertainty values for a given measurement are expressed as a range, at a given confidence level (e.g., "At the $95 \%$ confidence level, the object weighs $53 \pm 2.7$ kilograms"). 
HNF-3954 Rev. 0

6. The standard deviation of the measurement errors is calculated using the following formula ${ }^{10}$ :

$\begin{array}{ll}s & s=\sqrt{\frac{\sum(x-\bar{x})^{2}}{n-1}} \\ s & \text { Summation of individual terms } \\ x & \text { Standard Deviation } \\ \bar{x} & \text { Measurement Error } \\ n & \text { Sample Mean Measurement Error }\end{array}$

7. The standard deviation is used to calculate a confidence interval for the measurement error (uncertainty) using the following formula ${ }^{11}$ :$$
\bar{x} \pm t_{1-\alpha} \times S_{e}
$$$$
\bar{x} \quad \text { Sample Mean Measurement Error }
$$$$
s_{e} \quad \text { Standard Error of the Mean; } \frac{s}{\sqrt{n}} \text { for small samples. }
$$ \\ $t \quad$ Two-tailed $t$-distribution value for sample size $n$ and confidence level \\ $1-\alpha$ (e.g., at 2 sigma, $95 \%$ confidence level, $1-\alpha$ equals $1-0.95$, or $\alpha$ \\ $=0.05$ )
}

For this example, the calculated standard deviation would be (to 4 significant digits) 1.246 , the $t$-value would be 4.303 , and the confidence interval would be expressed as, "At the 95 percent confidence level, the measurement error (uncertainty) is $0.5067 \pm 3.094$ pounds."

When the confidence interval calculation is applied to measurement error, two numbers are produced. The first number, 0.5067 pounds, represents the mean measurement uncertainty; the measurement "bias". The second number, \pm 3.094 pounds, represents a $95 \%$ confidence interval centered about the mean measurement uncertainty, a measure of the "random" uncertainty of the 


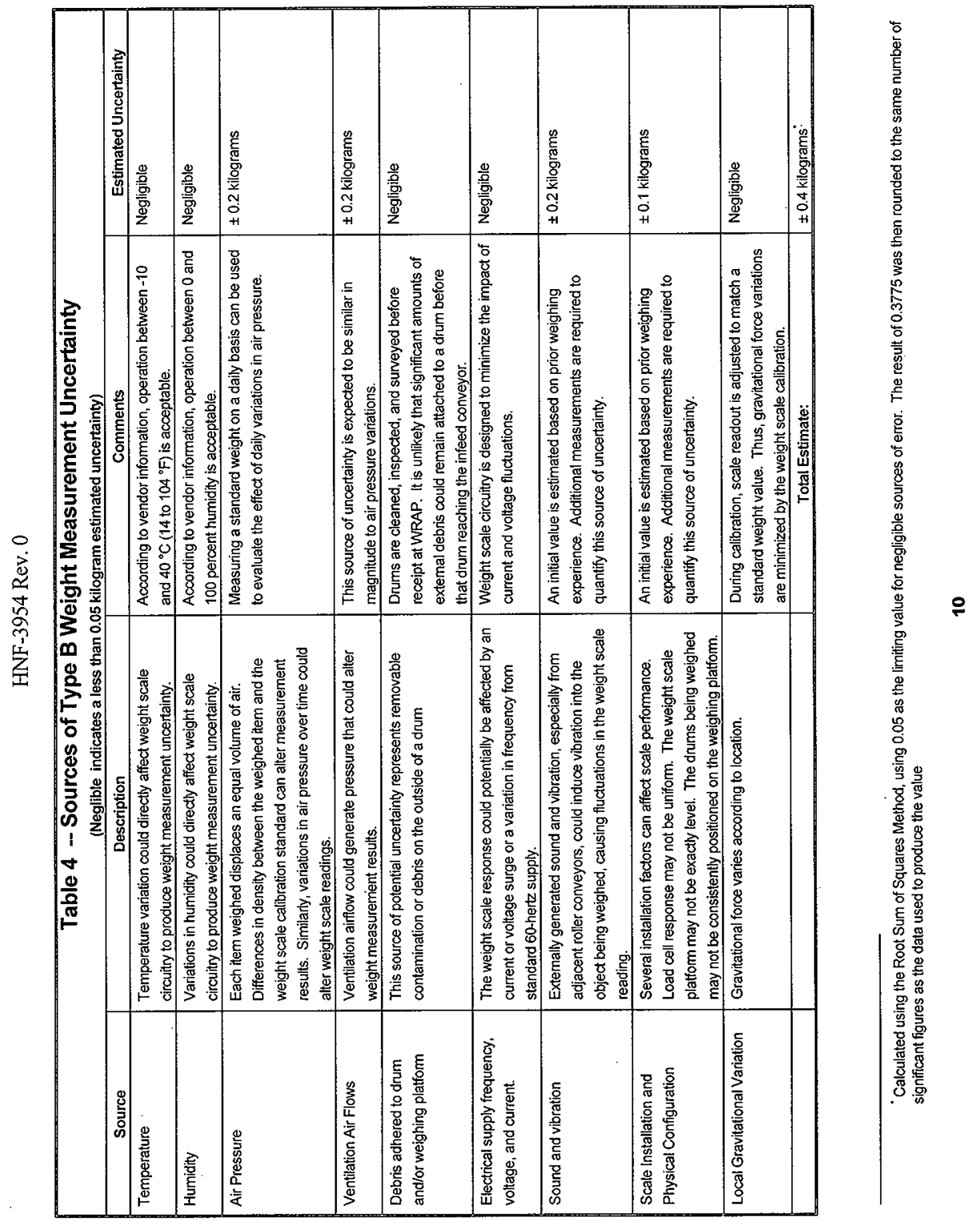




\section{References}

1 Instrument Calibration Instruction, WRP-Cl-0501, "Fairbanks Weight Scales Used in Wrap", Revișion 1, Change $B$.

${ }^{2}$ Vendor Information, "Fairbanks Scales Operating Manual, Digital Indicator Model H90-5200, Bulletin SJ 4398".

${ }_{3}^{3}$ Waste Management Hanford Federal Senvices, Data Sheet W1-98-00806/I for PMS Number W1-00388,

${ }^{4}$ Rice Lake Weighing Systems, Weight Certification 416814, NCS NIST Reference Number 503900, 8-31-98.

${ }^{5}$ ANSI NCSL 2540-1-1994, "Calibration Laboratories and Measuring and Test Equipment - General Requirements", July 27, 1994, section 10.2, page 8, American National Standards Institute,

${ }^{6}$ Ibid., Fairbanks Scales Operating Manual

${ }^{7}$ Ibid., ANSI NCSL Z540-1-1994,

${ }^{8}$ NIST Technical Note 1297, "Guidelines for Evaluating and Expressing the Uncertainty of NIST Measurement Results", 1994 Edition, section 3, Barry N. Taylor and Chris E. Kuyatt, United States Department of Commerce.

${ }^{9}$ lbid., NIST Technical Note 1297

${ }^{10}$ Mario F. Triola, 1992, Elementary Statistics, Addison-Wesley Publishing Company, Inc., Englewood Cliffs, New York

11 Jonathan D. Cryer and Robert B. Miller, 1994, Statistics for Business, Data Analysis and Modeling, Wadsworth Publishing, Englewood Cliffs, New Jersey

${ }^{12}$ Operating Procedure WRP1-OP-503, Revision E-8, "Move Waste Drums Throughout WRAP Facility", 12/28/98

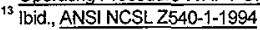




\section{Appendix A -- Weight Uncertainty Spreadsheet}

A spreadsheet was constructed to evaluate the effects of sample size and expected variation on weight measurement uncertainty. The spreadsheet "RANDOM" function was used to simulate variations in measured weights. The "RANDOM" function generates a pseudo-random number between 0 and 1 . Given a large number of trials (e.g., Greater than 30 ), the value of the "RANDOM" function tends toward 0.5. Although it is recommended that all weight operations at WRAP be carried out in kilograms, this spreadsheet utilizes pounds; to be consistent with current weight units at WRAP.

The spreadsheet allows input of the following variables:

1. Weight Number 1 in pounds (Weight1)

2. Weight Number 2 in pounds (Weight2)

3. Weight Number 3 in pounds (Weight3)

4. Expected Variation in pounds (Variation)

Weights 1,2, and 3 represent the three weights currently used to calibrate scales at WRAP. The expected variation represents the expected magnitude of fluctuations of measured values in comparison to the actual standard weight values. In this example, a fluctuation of \pm 0.5 pounds indicates that the measured value will be within 0.5 pounds of the standard value $95 \%$ of the time.

The combination of the standard weight value, the expected variation, and the "RANDOM" function is used to simulate a range of measured values. Trials are then simulated using different numbers of replicate measurements. Every simulated measurement is subtracted from the matching standard value to obtain a measurement error value. The measurement error values are total for each trial.

Three trials were performed with different levels of expected variation. The results of these trials are included as is a print-out of the spreadsheet formulas used to generate the trials. 
HNF-3954 Rev. 0

Trial \#3

Expected Variation: $\quad+/-0.6$ pounds $(0.3 \mathrm{~kg})$

Confidence Level: $\quad 95 \%$ (2 Sigma)

\section{Number of Measurements}

Taken

\begin{tabular}{|c|c|c|c|c|c|}
\hline & 3 & 6 & 9 & 15 & 30 \\
\hline 1 & 3.755802 & 0.979225 & 0.819461 & 0.499508 & 0.247637 \\
\hline 2 & 3.452397 & 1.057751 & 0.612726 & 0.415081 & 0.364622 \\
\hline 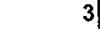 & 3.608215 & 0.922295 & 0.283669 & 0.513157 & 0.262175 \\
\hline 4 & 2.112376 & 0.988618 & 0.6747 & 0.498624 & 0.363386 \\
\hline 5 & 2.511297 & 1.11986 & 0.798969 & 0.503584 & 0.318992 \\
\hline 6 & 3.749443 & 0.824266 & 0.803391 & 0.516003 & 0.340103 \\
\hline 7 & 2.469624 & 1.233685 & 0.664379 & 0.505847 & 0.37257 \\
\hline 8 & 529 & 0.66 & 0.761952 & 0.601317 & 0.3363 \\
\hline 9 & 0.5 & 1.253623 & 0.746464 & 1436 & 0.296 \\
\hline 10 & 3.704454 & 0.889977 & 0.755745 & 0.499011 & 0.3346 \\
\hline
\end{tabular}

Mean:

$\begin{array}{llllll}2.735101 & 0.993639 & 0.692146 & 0.493357 & 0.323707\end{array}$ 


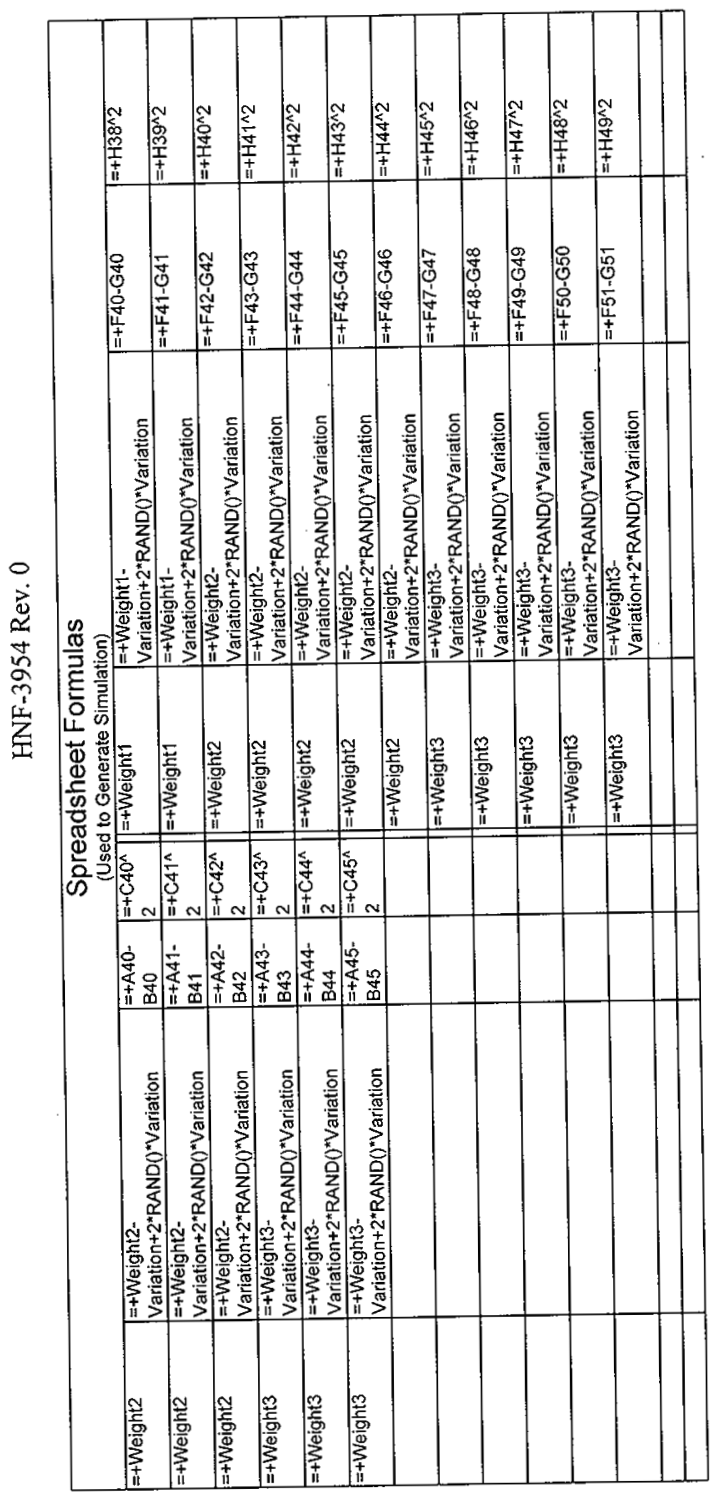




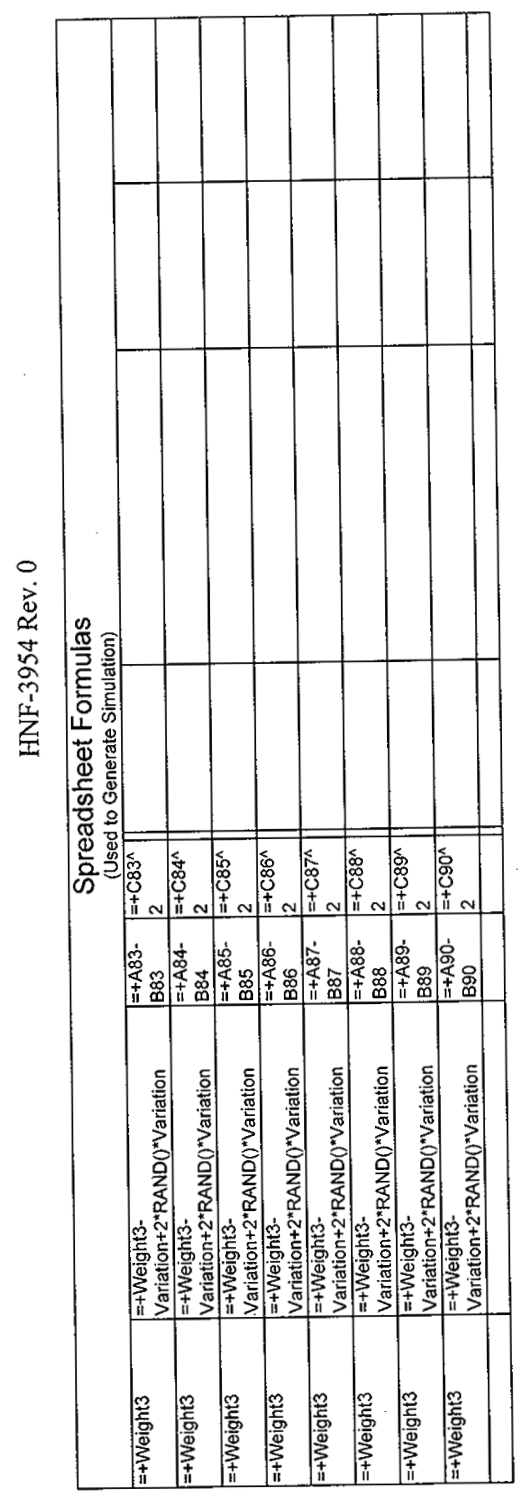




\section{DISTRIBUTION SHEET}

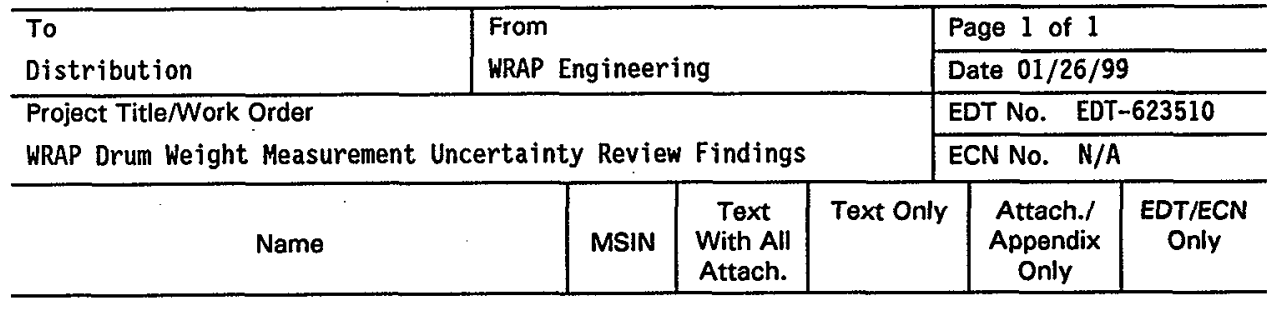

JC Givens

T4-52

$x$

KL Humphrys

T4-52 $X$

WG Jasen

T4-05

$x$

JK Kersten

T4-52

$x$

MP Lane

T4-52

$\mathrm{X}$

MA Purcel1

T4-52

$\mathrm{X}$

WR Thackaberry

T4-52

$x$

DH Watson, Jr.

T4-05

$x$

JR Weidert

T4-52

$x$

CE Wills

T4-52

$x$

DOE/RL Reading Room

H2-53

$x$

Engineering Files

B1-07

$\mathrm{X}$ 